Numbers of Notifications of Whooping Cough and Deaths According to Age in England and Wales 1969-74. Percentages are Given in Parentheses

\begin{tabular}{|c|c|c|c|c|c|c|c|c|c|c|c|c|c|c|}
\hline \multirow{2}{*}{ Age } & \multicolumn{2}{|c|}{1969} & \multicolumn{2}{|c|}{1970} & \multicolumn{2}{|c|}{1971} & \multicolumn{2}{|c|}{1972} & \multicolumn{2}{|c|}{1973} & \multicolumn{2}{|c|}{1974} & \multicolumn{2}{|c|}{ Total } \\
\hline & Notifications & Deaths & $\overline{\text { Notifications }}$ & Deaths & Notifications & Deaths & Notifications & Deaths & Notifications & Deaths & Notifications & Deaths & Notifications & Deaths \\
\hline $\begin{array}{l}<3 \text { months } \\
3-6 \text { months } \\
6 \text { months- } \\
1 \text { year }\end{array}$ & $\begin{array}{l}102(2 \cdot 0) \\
181(3 \cdot 6) \\
345(6 \cdot 9)\end{array}$ & $\begin{array}{l}3(50 \cdot 0) \\
1(16 \cdot 7) \\
0\end{array}$ & $\begin{array}{r}278(1.7) \\
614(3 \cdot 7) \\
1114(6 \cdot 7)\end{array}$ & $\begin{array}{l}5(33.3) \\
6(40 \cdot 0) \\
2(13 \cdot 3)\end{array}$ & $\begin{array}{r}361(2 \cdot 2) \\
614(3 \cdot 7) \\
1177(7 \cdot 0)\end{array}$ & $\begin{array}{c}13(50.0) \\
7(26.9) \\
2(7.7)\end{array}$ & $\begin{array}{r}34(1 \cdot 6) \\
67(3 \cdot 2) \\
162(7 \cdot 8)\end{array}$ & $\begin{array}{ll}1 & (50.0) \\
1 & (50.0) \\
0 & \end{array}$ & $\begin{array}{r}40(1 \cdot 6) \\
87(3 \cdot 6) \\
203(8 \cdot 3)\end{array}$ & $\begin{array}{l}2(100) \\
0 \\
0\end{array}$ & $\begin{array}{r}316(2 \cdot 0) \\
547(3 \cdot 4) \\
1312(8 \cdot 1)\end{array}$ & $\begin{array}{l}6(46 \cdot 2) \\
3(23 \cdot 1) \\
3(23 \cdot 1)\end{array}$ & $\begin{array}{l}1131(1.9) \\
2110(3 \cdot 6) \\
4313(7 \cdot 3)\end{array}$ & $\begin{array}{r}30(46 \cdot 9) \\
18(28 \cdot 1) \\
7(10 \cdot 9)\end{array}$ \\
\hline & $4363(87.4)$ & $2(33 \cdot 3)$ & $14591(87 \cdot 9)$ & $2(13.3)$ & $14640(87 \cdot 2)$ & $4(15 \cdot 4)$ & $1806(87 \cdot 3)$ & 0 & $2107(86.5)$ & 0 & $14050(86 \cdot 6)$ & $1(7 \cdot 7)$ & $51557(87 \cdot 2)$ & $9(14 \cdot 1)$ \\
\hline Total & $4991(100)$ & $6(100)$ & $16597(100)$ & $15(100)$ & $16792(100)$ & $26(100)$ & $2069(100)$ & $2(100)$ & $2437(100)$ & $2(100)$ & $16225(100)$ & $13(100)$ & $59111(100)$ & $64(100)$ \\
\hline
\end{tabular}

of immunization, from about 1000 just after the second world war to 100 in 1957. In 197413 deaths were recorded in England and Wales. The decline in mortality probably reflected improved management of the illness. Though the incidence of disease was low in infants under 3 months old the fatality rate among children in that age group with whooping cough remained high (see table).

Studies into whooping cough by the Epidemiological Research Laboratory of the Public Health Laboratory Service are continuing but some results (to be published) suggest that (a) currently used vaccines offer a high degree of protection against whooping cough, and $(b)$, even though mortality is low, whooping cough is still a severe illness, particularly in infants under 1 year of age. Illness seemed to be less severe in those children who contracted whooping cough despite being fully immunized than in those who were either only partially immunized or unimmunized.

\section{Adverse Reactions}

Evidence on adverse reactions to vaccines from the Committee on Safety of Medicines and the Epidemiological Research Laboratory indicates that the incidence of serious hazards is low and that all the conditions that have been reported as complications of vaccination may also occur independently of vaccination. Hence the Subcommittee on the Complications of Vaccination was set up in September 1974 under the chairmanship of Professor J. A. Dudgeon to evaluate reactions to vaccines.

Inquiries by the subcommittee into the practice of vaccination against whooping cough in Europe, North America, and Australia have shown considerable differences among countries in the immunizing materials used, schedules of immunization, and methods of ascertaining adverse effects. Nevertheless, most countries continue to immunize against whooping cough.

Studies of neurological illness, including convulsions, are planned to provide sound statistical evidence on rates of occurrence of encephalitis or encephalopathy in both recently immunized and unimmunized children. These studies will be valuable, though they will not provide information on the risk of immunization for some time. Nevertheless, all available information indicates that the hazard of whooping cough is greater than that associated with immunization.

\section{No Change in Policy}

The committee's unanimous view is that the policy of offering pertussis vaccine in infancy should not be changed, and this advice has been given to the Department of Health and Social Security. The implementation of this policy is especially important for the children of large families to reduce the risk of crossinfection to young babies in such households.

\section{Reference}

1 Chief Medical Officer, Department of Health and Social Security. Letter 17/74 to General Practitioners, Regional and Area Health Officers, 11 June 1974.

\footnotetext{
Academic Department of Medicine, Royal Free Hospital, London NW3 2QG

ELIZABETH WYN PUGH, M.B., M.R.c.o.G., Research Fellow (jointly with Department of Audiovisual Communication, B.M.A. House)

G. J. LLOYD, M.B., M.R.C.P., Research Fellow, King's Fund Record Project NEIL MCINTYRE, M.D., F.R.C.P., Reader in Medicine
}

In 1961 the cost of producing a British medical graduate was about $£ 10000 .^{2} \mathrm{~A}$ recent estimate suggests that it is now about $£ 25000 .^{3}$ For such a large investment the public might reasonably expect medical graduates to be of high quality and to have had a training appropriate to the needs of the community. There are grounds for disquiet about both of these expectations. Many teachers, particularly those who are examiners, are concerned about the quality of students at the time of graduation. The public, and some within the profession, complain that doctors do not communicate skilfully with patients and their families, that they are inadequate in caring for the dying and patients with psychiatric and geriatric problems, and that they lack awareness of the problems of community health.

Some teachers are not unduly concerned about the present situation, pointing to the rapid improvement which follows qualification, when house officers are exposed to the rigours and responsibilities of clinical work. Such progress undoubtedly 
occurs but it is not uniform. The standards of many doctors remain suboptimal. It would seem sensible therefore that essential knowledge, skills, and attitudes should so far as possible be mastered in the medical school before graduation when remedial action is easier. The factors in postgraduate training which lead to rapid improvement should be identified and incorporated into the undergraduate programme. This principle presumably underlies the policy of those medical schools in which final year students take increasing clinical responsibility.

\section{Defects in Curriculum}

We must ask why the performance of medical graduates is defective. An analysis in Edinburgh ${ }^{4}$ identified the following primary defects in the curriculum; they are common to most medical schools.

(1) An absence of defined educational objectives at all levels.

(2) A curricular structure that makes only limited allowance for varying interests, aptitudes, and rates of learning of different students.

(3) A curricular structure that does not easily allow amendment or modification with time.

(4) Over-crowding of the curriculum and over-teaching of factual material.

(5) Failure by students who lack clinical experience to appreciate the relevance of a great deal of preclinical teaching.

(6) Failure to reinforce science-based knowledge in the context of clinical problems in later years.

(7) Over-dependence on the use of the lecture as an all-purpose teaching method.

(8) A very limited use of teaching methods which develop self-reliant learning.

(9) Teaching and subsequent examination of subjects in individual isolation and with over-emphasis on factual recall.

(10) Widespread neglect of continuing student assessment with the possibility of student guidance at a time appropriate for further remedial teaching.

These defects cover the three main areas of educational effort - the school's aims, the methods used to achieve them, and the system of evaluation. The first defect, the absence of defined objectives at all levels, creates problems because without objectives it is difficult to set priorities, to construct a suitable curriculum, or to decide whether students have achieved their own aims or those set for them by the school.

The problem in most medical schools is not the absence of broad goals. All would contend that they aim to produce good doctors with a sound knowledge of medical science, skilled in diagnosis and therapy, committed to the prescrvation of health, and sensitive to individual human needs. But they seem to assume that these goals can be achieved merely by exposing students to their teaching programmes. This may be wishful thinking. Since the goals are inadequately reflected in the qualifying examinations and because they are not specified explicitly we do not know what criteria to use as evidence of success.

\section{Statement of Objectives}

A few organizations, medical schools, and departments have tried to state objectives clearly. The Association of American Medical Colleges, ${ }^{5}$ for example, suggested that students should be helped to acquire requisite knowledge in certain fields, to establish essential habits, and to achieve basic skills, etc. Similarly a department of anaesthetics suggested that teachers should provide sufficient knowledge of the vocabulary of the subject to make it comprehensible and illustrate the relevance of the basic sciences to the principles of anaesthesia. These objectives are commendable but they concentrate on the performance of the teachers, and therefore it is not clear what students would have to do to show that the course has been successful.

The idea that goals and objectives could be more than vague statements of intent was first put forward in 1933 by Tyler, ${ }^{6}$ who suggested that objectives should be formulated in terms of the changes in student behaviour which it was intended to bring about by learning. This approach to the definition of objectives has been received enthusiastically in some quarters (perhaps for this reason others have rejected it on principle). There are a number of good short texts on the subject, and those of Mager are excellent. ${ }^{1{ }^{7}} \mathrm{He}$ points out that the statement of an objective is useful only to the extent that it specifies what the learner must be able to do or perform when he has achieved the objective. It would be useful to state that the student "should be able to test the integrity of all the motor and sensory divisions of the trigeminal nerve" or that he "be able to perform a lumbar puncture." Both statements tell us what the student will be doing when he demonstrates his mastery of the objective. "To develop an understanding of the application of basic sciences in anaesthetics" is not a useful objective: it may be an important one but it is stated so vaguely that it is impossible to recognize the iritent of the person who selected it. In medical education many of our most important goals are vaguely expressed. We ask that students should "know," "understand," or "appreciate" something. Such goals are abstractions since they do not help us to identify whether, or when, they have been achieved. Fortunately their use is not precluded, since they can be analysed and then defined in terms of performances. ${ }^{8}$ When this is done it is easier to plan appropriate educational programmes and to evaluate their success.

When an objective* is written the described performance should match as closely as possible the real intent of the objective. Ideally they should be identical, but sometimes real life situations are inappropriate for the purposes of instruction or testing. For example, a senior medical student should be able to manage a cardiac arrest but it would be unreasonable to test him on the real thing. A clinical simulation or a manikin might be valid substitutes. An essay on the subject would clearly be less appropriate as the required performance is much further from the intent of the objective. When we use simulated conditions for the purposes of evaluation we infer that the student can do something after we have watched him do something different. The inference grows as the test performance diverges from that called for in the real life situation. How big an inference can we tolerate ? Mager ${ }^{8}$ points out that it depends on the consequences of failing to satisfythe real intent of the objective. If they are not serious a large assumption may be reasonable; if they are serious even a small assumption may be dangerous and it would be better to construct a more appropriate test. This may be timeconsuming and difficult and the effort to be expended on it must also depend on the seriousness of the consequences of failure.

\section{Criteria of Acceptable Performance}

When writing objectives criteria of acceptable performance should be specified as a standard against which the student may assess his progress and the teacher his teaching programme. Minimum acceptable performance may be stipulated in many ways-in terms of the time taken to perform a task, the number of correct responses to a series of questions, or the percentage of abnormal physical signs detected, etc.

In trying to apply the principles outlined above many people have fallen into a trap. In communicating the amount of factual knowledge which the student should have they have followed Mager's advice to "write a separate statement for each objective; the more statements you have, the better chance you have of making clear your intent." 1 They have ended up with a voluminous document and with individual objectives so detailed that they are virtually a complete statement of the factual information

*From this point the word "objective," except when quoted directly from the work of others, will be used only with the meaning outlined in the preceding paragraph-that is, in terms of the performance needed to show that the objective has been achieved. The words "aim" and "goal" will be used less precisely to denote either the general purpose or the desired outcome of educational effort. 
to be recalled. These detailed factual objectives are easier to write than objectives which involve the handling of information, but they are often inappropriate, since most teachers want their students to use information not to memorise it. The consequence of forgetting bits of information are usually trivial as they can be obtained from various sources of reference, but it is a serious matter not to be able to use information. This defect can rarely be corrected quickly by reference to books.

To help in the construction of objectives Bloom and his colleagues devised their Taxonomy of Educational Objectives, published in two small volumes. ${ }^{910}$ In the first they concentrate on objectives which deal with the recall or recognition of knowledge (of the "cognitive domain") and the development of intellectual abilities and skills. They propose a hierarchical arrangement. Simple knowledge objectives are at the lowest level while "comprehension," "application," "analysis," "synthesis," and "evaluation" are listed in ascending order. Higher objectives subsume those which are lower in the hierarchy, and if a high level objective is achieved it can be assumed that the student can perform at the lower level.

The Taxonomy has led many teachers to realize that though the goals they value involve higher taxonomic levels their instruction and evaluation are aimed chiefly at the low level of the transmission and recall of knowledge. Unfortunately, however, many are put off by the jargon used.

In writing higher level objectives the emphasis should clearly be on principles rather than detail. Mager ${ }^{1}$ gives an excellent example. "The student must be able to write a musical composition with a single tonal base. The composition must be at least 16 bars in length and contain at least 24 notes. The student must demonstrate his understanding of the rules of good composition by applying at least three of these in the development of his score. The student is to complete his composition within four hours."

The same kind of objective can be written for clinical medicine. For example: "In the clinical notes recorded on each inpatient under his care the student will demonstrate his ability to interpret and utilize clinical information by (1) formulating from his clinical data base a list of those problems which require activity or attention; (2) constructing, for those problems requiring activity, plans which cover the collection of further information and which describe the treatment he would recommend; (3) recording the progress of each active problem, noting the results of requests for further information as they return, recording his assessment of them and of changes in symptoms and physical signs, and writing plans for further investigation or change of treatment. The student's performance will be acceptable if his reasoning is clear in the notes and if he can defend his statements and decisions on the basis of common sense or established practice or by reference to authoritative sources such as recent texts or journals."

\section{Student's Attitudes}

In training a doctor it is important to promote skills and appropriate attitudes as well as the objectives of the cognitive domain. A classification scheme for skills has proved very difficult to draw up because of the wide variety of activities covered. Fortunately, the guidelines set out by Mager ${ }^{7}{ }^{8}$ make it relatively easy to write objectives, in this field.

Attitudinal objectives are much more difficult to write. A student's attitudes depend partly on his knowledge and partly on an emotional background of interacting social, psychological, and educational factors. Attitudes are very important since they greatly influence the student's reaction to a wide variety of stimuli and they may dictate the direction and the intensity of his response. They are powerful motivating forces. Some teachers believe that they cannot influence a student's attitude but Miller ${ }^{11}$ pointed out that the learning of attitudes is continuous and influences future behaviour more than the input of knowledge (to which so much attention is directed). If there are attitudes towards work, patients, and colleagues and towards certain aspects of health care that students should learn we should promote them. We should state them explicitly and cater for them.

To facilitate the definition of attitudinal objectives Bloom and his colleagues produced the second volume of their Taxonomy. ${ }^{10}$ It deals with the "affective domain" and proposes another hierarchy ranging from "willingness to receive stimuli" to "characterization by a value or value complex." A simpler approach to writing "affective" objectives, which are usually stated as broad goals, has been suggested by Mager. ${ }^{7} \mathrm{He}$ argues that a statement about a person's attitude is a statement of prediction based on that person's behaviour either in respect of what he says or what he does. For example, we can state that a student has a favourable attitude towards psychiatry if he says favourable things about it, if he seems happy while studying it, and if voluntarily he spends a lot of time in the psychiatric wards or clinics. The behaviours on which such statements are based are called "indicator" behaviours and they can be used as a performance (or test) to indicate whether an attitudinal objective has been achieved. Broad attitudinal goals can be analysed to decide on appropriate indicator behaviours. This process of "goal analysis" is invaluable for creating useful objectives.

Clearly there are many problems in using objectives in the way described above. Useful objectives are not easy to write and acquiring the skill takes time. Few teachers are sufficiently motivated to sacrifice the time required for such a labour. Ideally, the whole faculty should be responsible for choosing the objectives, and should begin by specifying the overall aims of the school. This helps to co-ordinate the work of departments. Otherwise the teaching and learning in any given department may, as is so often the case, be inappropriate to the educational process of the school as a whole. Unfortunately, an interest in objectives often arises in only one department, which may therefore become isolated from rather than integrated with the rest of the teaching programme. Objectives may not be agreed on even within a single department, and analysis of them may highlight genuine disagreements which demand a fundamental rethinking.

\section{Major Advantages}

Despite the problems of implementation there are major advantages in using objectives stated in terms of a desired performance. The first of these is improved communication. Students will be better motivated if presented with clear and relevant objectives, and there is evidence that they learn more successfully. ${ }^{12}$ Beard ${ }^{13}$ wrote: "Where goals are too remote there is a tendency to let work slide in the belief that it can be made good later; it they are not clearly defined the result may well be apathy and inactivity. A few years ago it was fairly commonly reported of students in clinical courses in medical schools that they did little work and spent too much time in social activities and playing games. Inquiries showed, however, that students who behaved in this way had practically no responsibility in their activities and little guidance as to what forms the activities should take. In all the schools, of course, students are taught by consultants during ward rounds and are allowed to examine a few patients and to make some tests, but there may be no welldefined duties to fill the day and, moreover, in some medical schools consultants advise their students not to read ... It hardly requires the investigations of psychologists to appreciate that some kind of feedback is needed to enable anyone engaged in learning to find out whether he is doing what is required of him. If he is not told whether he succeeds and has no means to judge for himself there is little point in making further efforts. Until the learner has established standards by which to assess his own performance he needs detailed and prompt criticism to redirect his learning." 
Clearly stated objectives also help teachers to communicate with each other since they can see more clearly the purpose of instruction given in another department. It students have to achieve objectives before passing on to other courses the teacher of those courses will appreciate the student's developing capabilities. This should help to avoid unnecessary repetition and promote better integration within the teaching programme.

That the statement of objectives would improve curriculum planning seems self-evident. Clinical teachers asked to declare their real objectives usually argue for skills such as ability to collect clinical information in a thorough and reliable fashion and to evaluate data and to solve unfamiliar problems, yet these receive relatively little attention in conventional curricula. It is common sense that planning a medical curriculum should begin by identifying those areas in which a student should acquire competence. Priorities may then be set and specific objectives delineated. After that it is relatively easy to arrange learning activities appropriate to the objectives and to fit them into the overall plan. With this approach decisions are focussed on the learner not on the teacher, and the student can shift his energies from engaging in feats of memory to acquiring the competence medical practice requires. ${ }^{14}$

\section{Evaluation of Competence}

A school must check the quality of its products. Currently we do it with a qualifying examination which largely relies on the recall of factual information. Clinical skills and the ability to handle clinical information are inadequately assessed and examinations do not reflect the real goals of most clinical teachers. This is unfortunate, because there is good evidence that it is the examination that dictates to most students what they must learn. "If success is determined by their ability to absorb and reproduce vast quantities of information, this is what they will do-even at the expense of other objectives which the faculty professes to prize but neither measures nor rewards." 15 With written objectives the task of evaluating students is relatively straightforward. It is only necessary to check whether they have mastered them, and this is simple when the test performance has been specified along with the conditions of the test and the criteria of acceptability.

Traditionally we have graded students by relating their performance to that of their contemporaries. In doing this we make a "norm-referenced" evaluation. There is a major objection to this system. No matter how well students perform, no matter how many meet or exceed the teacher's expectations only some will be allowed to consider themselves as competent. Conversely, no matter how poorly the group performs the best of them will be given a label (or grade) signifying success. ${ }^{8}$ Failing to acknowledge the success of the poorer performers in a good group has serious consequences for their educational development; refusing to acknowledge the failure of the best of a poor group, especially in a subject such as clinical medicine, can be dangerous. This approach is inappropriate in a medical school as there are many things which all students should know or be able to do. Success in achieving them cannot be evaluated by comparing one student with another. Instead we must compare the performance of each student with that called for in clearly defined objectives. That is a "criterion-referenced" evaluation, and implicit in its use is that the purpose of an educational programme is to help as many students as possible to achieve its important objectives. ${ }^{8}$

\section{Conclusion}

We have suggested that medical graduates lack qualities that many teachers and members of the public regard as characteristics of a good doctor. We have argued that these deficiencies might be made good by introducing into medical education appropriate and clearly defined objectives. We have outlined how they might be constructed and their advantages for students, teachers, examiners, and curriculum planners.

These objectives should reflect not only the true goals of the teachers but also the needs of society, and sources outside the faculty must be used in generating them. To quote Miller, ${ }^{11}$ "Traditionally objectives have been generated by academicians, faculty members appointed to their posts because of special qualifications in a biomedical discipline and committed to passing their knowledge and professional skills on to their students. However, this practice is under increasing attack by students, who protest that programme goals are more often dictated by faculty interests than student needs; by practitioners, who complain that academic rather than practical goals seem to dominate educational programmes; and by an increasingly aroused public, which finds physicians unresponsive to the health service needs of the entire population... The evidence is mounting that programmes based on educational objectives derived from faculty alone have had limited success in producing physicians prepared to serve the broad health needs of either developing or developed nations."

Walldren ${ }^{14}$ argues that social, economic, and political factors must be considered when decisions are made about the objectives of a medical school and the content of its curriculum. Purely academic aspects can be dealt with by the staff of individual medical schools, but the preparation of objectives which reflect these other factors could be facilitated with help and direction from a central co-ordinating organization. The General Medical Council, responsible both for protecting the public and for keeping a watching eye on the academic side of medical education, seems ideally suited for this purpose. We hope that it will vigorously promote curriculum planning and evaluation based on well defined goals and explicit objectives, and that it will actively contribute to this process by clearly indicating to teachers the public needs. These needs should be clearly reflected in the goals of our medical schools. Sadly this is rarely so. When such goals eventually emerge explicit objectives could clarify them and help to ensure not only that they achieved but also that they are seen to be achieved.

Dr. Wyn Pugh is supported by grants from the Nuffield Foundation and from CIBA Laboratories. Dr. Lloyd is supported by a fellowship from the King Edward's Hospital Fund.

\section{References}

1 Mager, R. F., Preparing Instructional Objectives. Belmont, California, Fearon, 1962.

${ }^{2}$ Hill, K. R., British Medical fournal, 1964, 1, 300.

3 University Grants Committee in Financing Medical Education. Dundee Association for the Study of Medical Education, May, 1975.

${ }^{4}$ Robson, J. R., in Curriculum Changes in United Kingdom Medical Schools. Dundee Association for Study of Medical Education, December, 1973.

${ }^{5}$ Association of American Medical Colleges, Fournal of Medical Education, 1953, 28, 57

6 Tyler, R. W., Educational Research Bulletin, 1933, 12, 196 (quoted by Kerr, J. F., Changing the Curriculum. London, University of London Press, 1968).

7 Mager, R. F., Goal Analysts. Belmont, California, Fearon, 1972.

${ }^{8}$ Mager, R. F., Measuring Instructional Intent. Belmont, California, Fearon, 1973.

${ }^{9}$ Bloom, B. S., et al., Taxonomy of Educational Objectives: I. Cognitive Domain. London, Longman, 1956.

${ }^{10}$ Krathwohl, D. R., Bloom, B. S., Masia, B. B., Taxonomy of Educational Objictives: II. Affective Domain. London, Longman, 1964.

11 Miller, G. E., in Development of Educational Programmes for the Health Professions, p. 26. Geneva, World Health Organization, Public Health Papers No. 52, 1973.

12 Varagunam, T., British fournal of Medical Education, 1961, 5, 213.

${ }^{13}$ Beard, R., Teaching and Learning in Higher Education, p. 62. Penguin Books, 1970.

14 Walldren, A. W., in Educational Strategies for the Health Profession. Geneva, World Health Organization, Public Health Papers No. 61, 1974

15 Miller, G. E., in Development of Educational Programmes for The Health Professions, p. 9. Geneva, World Health Organization, Public Health Papers No. 52, 1973. 